\title{
Erratum to: John Ruskin's Politics and Natural Law
}

\author{
Graham A. MacDonald
}

(C) The Author(s) 2018

G. A. MacDonald, John Ruskin's Politics and Natural Law, https://doi.org/10.1007/978-3-319-72281-8

DOI $10.1007 / 978-3-319-72281-8$

The figure illustration credits were missing in the original publication which is now updated.

The updated original online version if this book can be found at https://doi.org/10.1007/978-3-319-72281-8 